Archived version from NCDOCKS Institutional Repository http://libres.uncg.edu/ir/asu/

\title{
Appalachľan
}

B O O NE, NORTH CAROLINA

\section{Using Ecological Systems Theory And Density Of Acquaintance To Explore Resident Perception Of Entrepreneurial Climate}

\author{
By: Carol Kline, Nancy Gard McGehee, Shona Paterson, and Jerry Tsao
}

\begin{abstract}
Using the concepts of Ecological Systems Theory and Density of Acquaintance, this study was developed to explore the relationship between rural North Carolina residents' characteristics and their perceptions of entrepreneurial climate (e-climate). The North Carolina Community Assessment for Tourism and Entrepreneurial Climate Study was developed to determine which factors influence how residents view their community e-climate, an important antecedent to tourism success, in their community. Four categories of hypotheses were developed focusing on a resident's (1) residential tenure and nativity, (2) community involvement through volunteerism, (3) employment, and (4) entrepreneurial self-perception were developed. The first three categories included variables measuring residents' Density of Acquaintance; the fourth category addressed residents' perceptions of themselves concerning entrepreneurial activity in both their paid and volunteer work. Findings indicated that residential tenure and amount of volunteerism had the greatest influence on perceived e-climate. The most commonly differentiated factor of e-climate was consistently Training and Assistance.
\end{abstract}

Kline, C., McGehee, N. G., Paterson, S., \& Tsao, J. (2013). Using Ecological Systems Theory and Density of Acquaintance to Explore Resident Perception of Entrepreneurial Climate. Journal of Travel Research, 52(3), 294-309. https://doi.org/10.1177/0047287512465962. Publisher version of record available at: https://journals.sagepub.com/doi/full/10.1177/0047287512465962 


\title{
Using Ecological Systems Theory and Density of Acquaintance to Explore Resident Perception of Entrepreneurial Climate
}

\author{
Carol Kline', Nancy Gard McGehee², Shona Paterson ${ }^{3}$, and Jerry Tsao ${ }^{4}$
}

\begin{abstract}
Using the concepts of Ecological Systems Theory and Density of Acquaintance, this study was developed to explore the relationship between rural North Carolina residents' characteristics and their perceptions of entrepreneurial climate (e-climate). The North Carolina Community Assessment for Tourism and Entrepreneurial Climate Study was developed to determine which factors influence how residents view their community e-climate, an important antecedent to tourism success, in their community. Four categories of hypotheses were developed focusing on a resident's ( $I$ ) residential tenure and nativity, (2) community involvement through volunteerism, (3) employment, and (4) entrepreneurial self-perception were developed. The first three categories included variables measuring residents' Density of Acquaintance; the fourth category addressed residents' perceptions of themselves concerning entrepreneurial activity in both their paid and volunteer work. Findings indicated that residential tenure and amount of volunteerism had the greatest influence on perceived e-climate. The most commonly differentiated factor of e-climate was consistently Training and Assistance.
\end{abstract}

\section{Keywords}

tourism entrepreneurs, entrepreneurial climate, Ecological Systems Theory, Density of Acquaintance

\section{Introduction}

Entrepreneurs are an important catalyst to rural economic development (Deller and McConnon 2009; Goetz et al. 2010; Loveridge and Nizalov 2007; Stevens and Partridge 2011). Within the realm of rural tourism, entrepreneurs have sometimes been noted as the "persona causa" of tourism development (Koh 2002; Koh and Hatten 2002), making substantial positive economic, social, and environmental contributions to their communities (McKercher 1999; Russell and Faulkner 1999, 2004). Entrepreneurs are change agents, particularly in the tourism industry, that can yield significant impacts on their home communities (Barr 1990; Russell and Faulkner 2004). Tourism entrepreneurs can prevent gentrification by encouraging diversification in tourism products (Lordkipanidze 2002), stimulate growth in other economic sectors such as health care and agriculture (Lordkipanidze 2002), and preserve natural resources as in the case of the eco-preneur (Ferrari, Mondéjar-Jiménez, and Vargas-Vargas 2010). Tourism entrepreneurs are also vital to sustainability given their local connections and attachment to the community (McGehee and Kline 2008). This relationship between entrepreneur and community does not exist in a vacuum, however; support for small business growth and innovation, including localized financial, regulatory, physical, social, and educational policies and programs
(Koh 2002) is vital for entrepreneurial success. This is especially relevant for entrepreneurs specializing in tourism, as their local surroundings are often intrinsically linked to the tourism experience they are selling (McGehee and Kline 2008).

Policies and programs noted in the tourism literature as important to a tourism entrepreneur's success include the availability of training in starting a tourism business (Echtner 1995; Haber and Reichel 2007; Peters 2005; Victurine 2000), social networks and business-to-business linkages (Hitchcock 2000; Kirsten and Rogerson 2002; Volker and Sorée 2003), and coordination and cooperation between tourism entrepreneurs (Wilson et al. 2001). In an innovative study linking entrepreneurial attitude to economic growth, Beugelsdijk and Noorderhaven (2002, p. 18) demonstrated that "regions do differ in their entrepreneurial attitude." They purport that

\footnotetext{
'Recreation and Leisure Studies \& Center for Sustainable Tourism, East Carolina University, Greenville, NC, USA

${ }^{2}$ Virginia Polytechnic Institute and State University-Blacksburg, VA, USA

${ }^{3}$ Institute for Coastal Science and Policy, East Carolina University, Greenville, NC, USA

${ }^{4}$ International Studies \& Center for Sustainable Tourism, East Carolina University, Greenville, NC, USA
}

Corresponding Author:

Carol Kline, Recreation and Leisure Studies \& Center for Sustainable Tourism, East Carolina University, Mailstop I33, Greenville, NC 27858. Email: klinec@ecu.edu 
regions need a culture that is welcoming in order for entrepreneurship to thrive. For the purposes of this study, the sum of these phenomena will be referred to as entrepreneurial climate, or e-climate. This study utilizes Ecological Systems Theory (EST) and the concept of Density of Acquaintance (DA) as a foundation to develop a scale for measuring e-climate in a statewide study of 85 rural counties in North Carolina, United States.

\section{Evaluating Entrepreneurial Climate}

Evaluating a community's e-climate is a vital step in understanding its overall business climate and in formulating steps to improve it. Attempts to operationalize and evaluate individual e-climate factors have been fairly recent (Chatman, Atlman, and Johnson 2008; Low 2004; Markley, Macke, and Luther 2005; Rightmyre, Johnson, and Chatman 2004). Specifically, studies have found that sociocultural components of the community can greatly influence the success of the entrepreneur (Stevens and Partridge 2011), such as a "can-do attitude" (Flora and Flora 1993; Markley, Macke, and Luther 2005; Pages and Markley 2004), a leadership system that thinks beyond town borders to partner with other municipalities in the region (Crane and Meyer 2006; Rightmyre, Johnson, and Chatman 2004; Koh 2002), a shared sense of community identity (Flora and Flora 1993; Markley, Macke, and Luther 2005; Rightmyre, Johnson, and Chatman 2004), an openness to diversity (Chatman, Atlman, and Johnson 2008; Koh 2002; Markley, Macke, and Luther 2005; Pages and Markley 2004), a supportive attitude toward change and innovation (Bolton and Thompson 2004; Crane and Meyer 2006; Flora and Flora 1993, 1988; Koh 2002; Lerner and Haber 2000; Markley, Macke, and Luther 2005; Pages and Markley 2004), and a positive attitude toward local business (Crane and Meyer 2006; Lerner and Haber 2000; Markley, Macke, and Luther 2005).

To date, the development of a generalizable scale for measuring e-climate has been met with several challenges. For instance, while some elements of e-climate can be measured objectively, such as the quality and form of road systems within a region, the number and types of loan programs available, the years that a destination marketing program has existed, and the presence of small business award programs, other e-climate elements rely on subjective opinions of the community residents for evaluation, such as the receptiveness of government leaders to assisting small businesses, the outlook of the community on change and innovation, and the effectiveness of the educational programs that exist for entrepreneurs. While these subjectivities are certainly important to the development of a robust scale of e-climate, they are difficult to consistently measure. It is for this reason that this study focuses on perceptions of e-climate rather than actual policies and programs, and it is important to recognize previous research that concurs with this approach. Roosa et al. (2009) studied associations between self-reports and archival indicators of neighborhood quality. They concluded that in spite of the reality of existing programs within a community, "personal and familial characteristics may condition individuals to focus on particular aspects of their neighborhoods or to react more strongly to certain aspect of their neighborhood than others" (Roosa et al. 2009, p. 338). In other words, if residents are not aware or do not value a program, perception trumps reality.

A few scales have been developed to operationalize the overall entrepreneurial climate. While not specific to rural environments, the Panel Study of Entrepreneurial Dynamics (PSED) was piloted in 1998 as a program of the Entrepreneurial Research Consortium, and is the "culmination of the work of hundreds of scholars from 10 different countries, with the financial support of 33 member institutions" (Panel Study of Entrepreneurial Dynamics, n.d.). PSED is a longitudinal study focusing on the entrepreneurial process, individual entrepreneur history, entrepreneur attitudes and perceived strengths, entrepreneur behavior, and current situational factors of the business. While a thoughtful study, the entrepreneurial climate portion was somewhat limited in scope. In another study of entrepreneurship, Chatman, Altman, and Johnson (2008) developed a scale in order to measure business owners' perceptions of their community's entrepreneurial climate, and how it related to their community's level of entrepreneurship.

Certain individual characteristics might also influence how business owners perceive their community, including how long they have lived in the area, whether they work in the community, or if they are active in a volunteer capacity (Florin and Wandersman 1990; Jurowski and Brown 2001; Um and Crompton 1987). It is important for both governmental and non-governmental programs targeting entrepreneurs to understand how business owners perceive their e-climate so that they may market and promote their services efficiently and appropriately. It is equally vital to determine if and where there is a disconnect between these service providers and entrepreneurs, a prevalent issue discussed in the literature (Litchenstein, Lyons, and Kutzhavnova 2004; Macke 2007; Pages and Markley 2004).

A few scales exist specifically for rural entrepreneurial activities. The Rural Policy Research Initiative's Center for Rural Entrepreneurship developed the Energizing Entrepreneurs Program (E2), a resource for communities that would like to expand entrepreneurial activity by creating the right climate and assembling the necessary resources for existing or future entrepreneurs (Markley, Macke, and Luther 2005). The E2 program includes an extensive series of measures to evaluate a community's entrepreneurial climate. The University of Missouri's Community Policy Analysis Center also developed a scale specifically for rural communities, consisting of 50 questions about the community's climate. They sought to "quantify the perceived importance and performance of a community's entrepreneurial climate" (Rightmyre, Johnson, and Chatman 2004, p. 18) by creating the Rural Entrepreneurship Initiative. 
While each of these scales brings a great deal to the literature, there is still much work to be done in the area of e-climate. For example, little research has been conducted that evaluates the networks within the community to determine if and how they influence e-climate. These social interactions between family, friends, and acquaintances of the entrepreneur can form bonds that lead to greater economic capital. However, economic capital alone does not capture the rich construct of networks and associations (Macbeth, Carson, and Northcote 2004). Networks provide a social culture that either promotes innovation and economic development or hampers it. A study by Lerner and Haber (2000) examined the environmental, business, and personal factors contributing to the success of small tourism ventures including many aspects related to networks and institutional support within the community, and is an important resource for this study. Lerner and Haber (2000) also "confirmed the multidimensionality" of small tourism business performance and the complexity of environmental conditions. Such complexity demands an appropriate theoretical framework.

The theoretical perspective of Ecological Systems Theory (EST; also known as human ecology theory), accounts for the connection between and across many systems in an individual's environment and has been used in numerous fields, including urban planning, anthropology, economics, community development, and family studies (Bauer and Dolan 2011). EST emphasizes that an individual helps create the system. Systems within EST can include familial and neighborhood social systems, political networks, professional affiliations, environmental ecosystems, biological systems, and the coordination and planning of physical infrastructure. Because the elements of a supportive entrepreneurial climate interact in each of these systems, EST was adopted as the underlying framework for this study.

EST has been employed in tourism research primarily in the area of tourists' thoughts and behaviors before and during the travel experience (Woodside, Caldwell, and Spurr 2006; Woodside and Martin 2008). In addition, Fennell (2002) acknowledges the relevance of many types of systems theory in ecotourism research. Fennell and Butler (2003) propose the use of EST/human ecology theory in tourism development as it links human systems to those of the environment to help frame the pressures felt from tourism development. Similarly, Farrell and Twining-Ward note that tourism research needs to integrate its view of natural resource systems, social systems, and socioecological systems. They go on to suggest a "comprehensive tourism system [that] includes significant social, economic, geological and ecological components, along with the processes and functions that are essential for sustainability" (Farrell and Twining-Ward 2004, p. 117). Lacitignola et al. (2007) also suggest a socioecological system perspective to the management of a natural protected area. Padilla et al. (2010) apply an ecological systems perspective to their study on HIV/ AIDS and tourism in the Dominican Republic, while Larsen,
Calgaro, and Thomalla (2011) conceptualize stakeholder agency within socioecological systems in Thailand as it relates to resiliency in its tourism-dependent coast.

Density of acquaintance (DA) suggests that individuals in a community are linked with one another based on how they interact across various social systems. As a result, this can affect one's view of his or her community. The DA within a community can be defined as the extent to which community members interact with one another on a regular and personal basis at both formal levels (Freudenburg 1986), such as membership in a temple or service on a Board of Directors, and informal social networks, for example, neighborhood picnics. This current study will utilize the breadth of EST and the depth of DA to build on the aforementioned research to expand our knowledge about e-climate, particularly as it pertains to tourism-related entrepreneurship.

\section{Community Ties: Ecological Systems Theory and Density of Acquaintanceship}

To examine e-climate at the community level, creating geographic, socioeconomic and/or political parameters that define a community are necessary. The concept of "community" is widely used in research, with more than 94 distinct definitions (Hillery 1955, as cited in Obst, Smith, and Zinkiewicz 2002). For this study, the community was geographically defined as the home county of the respondent. This definition was selected because rural residents often associate themselves with their county, and much of the social and economic activity might occur across town or village demarcations (Henderson 2009). In addition, many of the entrepreneurial programs available to rural residents are county-level programs.

The ties between rural residents and the communities in which they reside are often strong; individuals may influence or be influenced by the community through numerous channels, including but not limited to family, work, social organizations, religious groups, and school. Ecological Systems Theory (EST) states that "individuals are embedded within environments with which they interact to influence development. Individuals actively process and construct beliefs and perceptions of their environments and, in turn, interact with their surroundings based on those beliefs or perceptions" (Roosa et al. 2009, p. 328). In other words, people's perceptions about their community can ultimately impact how they interact within it.

Bronfenbrenner (1979), who developed EST, explains that human development occurs from constant interaction over extended periods of time with other individuals and the environment. He provides five environmental structures that affect human development: microsystem, mesosystem, exosystem, macrosystem, and chronosystem. These are not separate and different systems, rather a set of relationships that 


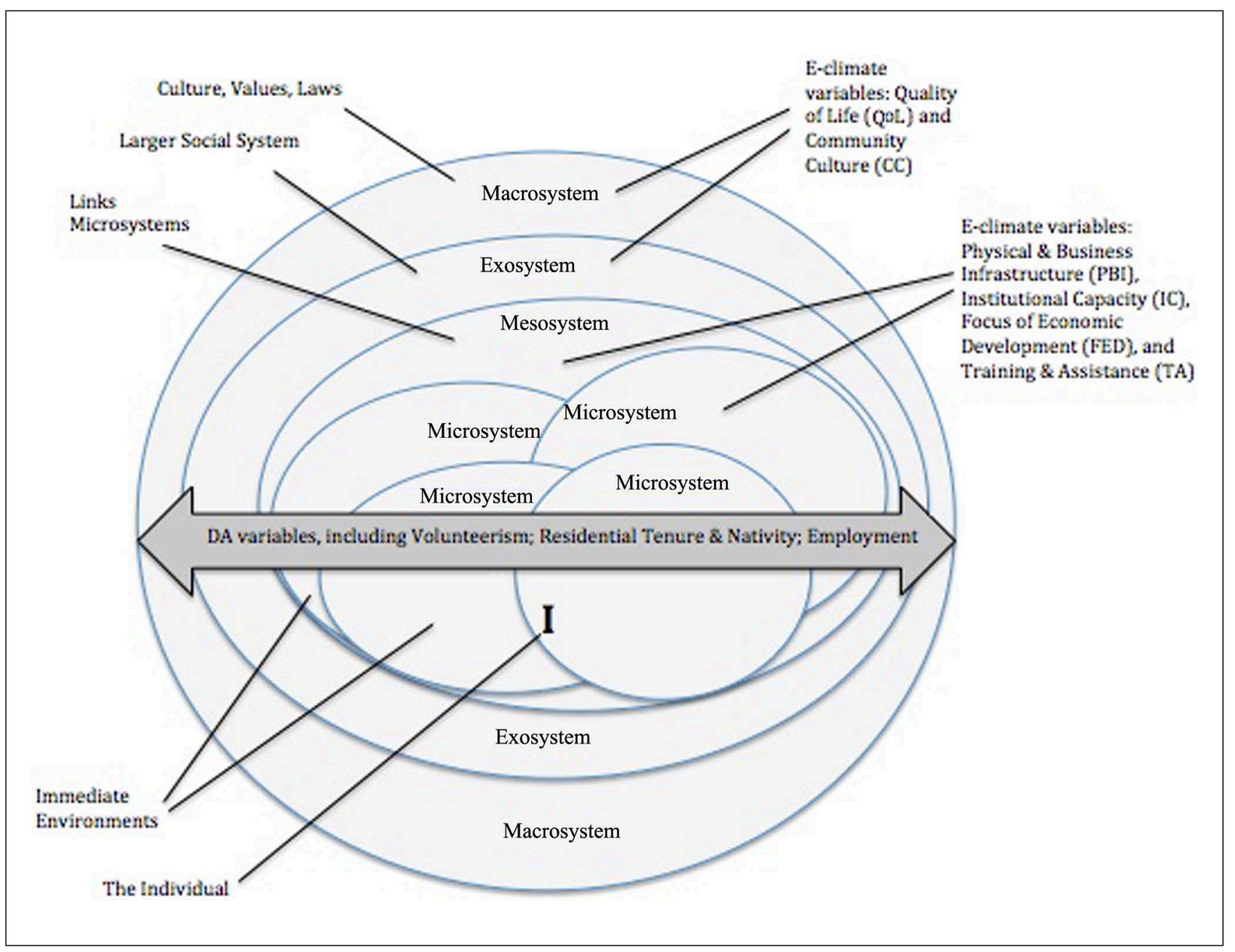

Figure I. Representation of ecological systems theory and entrepreneurial climate categories.

overlap, starting at the person's core (microsystem) and moving toward more distant relationships. At the microsystem level, the individual regularly comes in contact with the immediate environment, which includes family, friends, colleagues, and others. The mesosystem links the individual's microsystems together, such as a home and workplace. The exosystem is part of a larger system that indirectly influences the individual but is beyond their control (e.g., a parent's workplace - a child has no direct influence on the mother's employment). The macrosystem is composed of cultural values, customs, and laws (Berk 2000). The chronosystem includes the dimension of time within the environment; development transitions over the life course of the person (Bronfenbrenner 1979; Elder 1974).

The 36 e-climate elements measured in this study are incorporated into the EST systems, grouped into six categories in keeping with the entrepreneurship literature (which will be described in greater detail below): physical and business infrastructure, institutional capacity, focus of economic development, training and assistance, quality of life, and community culture. The first four categories correspond to one's EST micro- and mesosystems, while the two remaining categories correspond to the exo- and macrosystems. Combining the elements of e-climate with EST has great potential for the study of community and tourism development. The current study targets each of the system components of EST by asking residents to rate various elements of their entrepreneurial climate in their county (Figure 1).

While EST provides a framework for this study, DA theory provides an explanation for interaction across and within each of the systems. In other words, EST frames the breadth of influence across various systems of influence, while DA represents a depth that exists within each of the systems. An individual's personal associations formed by family, friends, and acquaintances are embedded in communities to differing degrees within the various systems represented in EST. When these ties are numerous and strong, it can often result in a high degree of clustering and low degree of separation (Huang and Tsai 2010; 
Fadahunsi, Smallbone, and Supri 2000; Perry 1999). For example, Susie is a member of a rural community. She may work at the bank with Grace (a formal measure of DA within her work EST microsystem), with whom she also attends the same church (an institution representing the larger culture and values or EST macrosystem), cochairs the Chamber of Commerce fundraising committee (EST micro- and mesosystem), and whose children also go to school with her children and engage in after-school activities together (informal EST microsystem). As a result of this high DA across various formal and informal EST systems, she knows that interactions with Grace at work will also influence her activities in church, the Chamber of Commerce, and her children. This awareness of a web of relationships with Grace may influence her behavior in any of these activities. Combining EST with DA creates a more robust model that accounts for both depth and breadth of influence.

Such high degree of DA typically occurs more frequently in rural communities than in urban communities. Informal networks of actors (family, friends, and acquaintances) can provide a social structure that encourages entrepreneurship within the community in that many of the skills and resources leading to business and organizational success exist outside of the firm itself (Van Laere and Heene 2003). This network of collaboration between various actors provides a balance between the risk-taking entrepreneur and the community's support, especially for rural entrepreneurs. Small businesses in rural areas have limited financial and technical support as they face difficulty competing against their larger counterparts (Braun and Hollick 2006). Social networks can help to minimize the transaction costs of operating in the market because the networks serve as conduits for the flow of helpful information, thereby facilitating goal achievement. For example, Matthews, Pendakur, and Young (2009) compared how networks are used in rural and urban areas to leverage job-finding and discovered that long-term residents in rural areas use both strong and weak ties much more frequently than do newcomers to find employment. This study adopts this general orientation in examining how various manifestations of acquaintance density influence resident perception of their community, and in this case, their community's entrepreneurial climate. In particular, this study will focus on participants' residential tenure, nativity, and volunteerism within the community as variables signaling a resident's DA.

Residential tenure and nativity have been found to play a role in their overall impression of the community in much of the tourism literature (Florin and Wandersman 1990; Hao, Long, and Kleckley 2011; Jurowski and Brown 2001; Um and Crompton 1987). Um and Crompton (1987) used residential tenure and heritage to define a resident's attachment level to a community. The more involved residents are in their community, the more optimistic they are about their quality of life (Jurowski 1998; Perkins et al. 1990). Additionally, these involved residents can influence policy makers into formal actions that lead to a higher quality of life within the community.
Matthews, Pendakur, and Young (2009) found that being a member of specific community organizations increased the likelihood of an individual using her or his networks to find a job. Likewise, Erickson (2003) found that involvement in community organizations extended a resident's network reach and diversity. The active engagement allowed the residents to empower themselves to affect positive change, especially in small communities (Perkins 1995; Zimmerman 1990). Hung, Sirakaya-Turk, and Ingram (2011) explored public participation in community-based tourism development and found that participation levels depended more on the opportunity and ability to participate rather than on the perceived outcomes of the development. Hwang, Stewart, and Ko (2012, p. 339) observed that "building communitybased coalitions . . . is a step toward long-term sustainability." In their study, Hwang, Stewart, and Ko were examining the participation of residents in tourism planning and development; however, the same sentiment regarding public participation could be true in many forms of community development. In a particular case of collaboration between tourism businesses and DMOs, Zach (2012) found that the relationship (and level of collaboration) with tourism partners had a significant impact on the development of new services within the DMO. While that study examined the impacts of community and business relationships on the DMO, the findings are applicable here in that the level of networks, partnering, and volunteerism within a community can affect the forms and level of economic development within that area. Asking respondents to report volunteerism activities and involvement in other local organizations will provide measurable variables to help gauge DA. A close examination of the types of volunteerism may help to fill a gap in the literature regarding specific organizations that are integral for successful entrepreneurial tourism development.

In addition to residential tenure, nativity, and volunteerism, one's individual perception, both of themselves and of their communities, plays a valuable role in not only DA but which networks one chooses to cultivate and trust. Roosa et al. (2009, p. 339) stated that community-based research should pay attention to "perceptual biases of individuals, for the way individuals perceive, organize and evaluate information about the neighborhood environments, is likely to improve the effectiveness of researchers' models of adjustment. After all, people react to the way they see their environment rather than to archival statistics describing the environment." It is for this reason that in addition to residential tenure, nativity, and volunteerism, individual entrepreneurial self-perception will also be considered in this study.

\section{Purpose of This Study/Research Questions}

For the purposes of this study, DA and EST will be used together as a way to explore the relationship between rural North Carolina residents' characteristics and their perceptions of entrepreneurial climate. EST forms the overall 
framework for the measurement of e-climate, while DA provides the networks that connect the various components of EST with the residents of rural North Carolina. The North Carolina Community Assessment for Tourism and Entrepreneurial Climate Study was developed and implemented to determine which factors, if any, influence how residents view the e-climate of their community. In this case, community was geographically delineated at the county level. Below are the research questions addressed in this paper.

1. How does residential tenure and nativity affect the way respondents rate their community's e-climate?

2. How does level of volunteerism affect the way respondents rate their community's e-climate?

3. How do employment variables affect the way respondents rate their community's e-climate?

4. How does an individual's entrepreneurial selfperception affect the way they rate their community's e-climate?

5. Are there patterns in the way the elements of e-climate are viewed according to the structure of Ecological Systems Theory?

\section{Methods}

\section{Instrument Development}

A framework of variables was designed based on the theoretical frameworks of EST and DA, the existing literature on e-climate (Koh 2002; Pages and Markley 2004; Rightmyre, Johnson, and Chatman 2004), and personal correspondence with authorities in entrepreneurship research (D. Markley, personal communication, September 2006; C. Moga-Bryant and L. Scott, personal communication, September 2006) to create The North Carolina Community Assessment for Tourism and Entrepreneurial Climate Study. The e-climate questions were partially derived from the Rural Entrepreneurship Initiative Survey Tool (Rightmyre, Johnson, and Chatman 2004) and Energizing Entrepreneurs Readiness and Assessment Tools. The part of the survey instrument dedicated to perceptions of the community's entrepreneurial climate totaled 36 items. The questions that contained multiple items were rated using a 5-point Likert-type scale, where $1=$ strongly disagree, 2 = disagree, $3=$ not sure, $4=$ agree, and 5 = strongly agree.

A hardcopy version of the questionnaire was piloted on three groups representative of the target population. A total of 46 usable questionnaires were returned and changes were made to the demographic, occupational, and community involvement section of the instrument. In addition, three experts each in entrepreneurship, survey design, and rural development provided feedback on the instrument. A pilot test was run as an online version and final edits to the instrument were made. The survey itself was conducted in a $100 \%$ online environment. It is important to note the e-climate metric employed was perceived e-climate rather than an absolute quality or quantity for a community. While perception does not always correlate with reality, it is important to understand how residents view their community climate, and more specifically for this study, the ecological systems in which they exist.

\section{Study Area}

North Carolina (NC) is consistently the sixth most visited state in the nation, generating $\$ 17$ billion in direct spending (North Carolina Department of Commerce 2011). Visitation and spending within rural North Carolina continues to steadily rise. The vast majority of counties included in the study reported some form of local tourism development programming (Kline 2006). Eighty-five of North Carolina's 100 counties are designated as rural by the NC Economic Rural Development Center. While counties are an artificial parameter, local residents do associate themselves with the identity and lifestyle of the county. As local government and organizations define service-areas with the county line, community will be defined as such in this study. All 85 rural counties were targeted for the study, representing a population range from 4,170 to 150,800 .

\section{Sampling and Distribution of Survey}

This study was meant to explore the relationship between rural North Carolina residents' characteristics and their perceptions of entrepreneurial climate. As mentioned previously, while the tourism industry is composed of both entrepreneurs and other types of businesses, the literature points to strong connections between a supportive entrepreneurial environment and successful tourism development. Tourism entrepreneurs may participate in non-entrepreneurial activities, both within and outside of the tourism industry. Rather than attempting to isolate a specific group of individuals who identify themselves solely as tourism entrepreneurs, or even entrepreneurs in general, this study opted for an approach utilizing a random sample of the general population within each of the participating communities. In this manner, the researchers were able to capture the overall perceptions of e-climate within the communities.

As mentioned previously, the entrepreneurial climate data were collected online. Dillman's design principles for Web surveys (Dillman 2000) were followed. The sample was drawn from the population older than age 18 in the targeted counties using a two-pronged approach. First, an email listing was obtained from a national mailing company that provides data and related services for direct mail campaigns. Second, a purposive sampling approach was used by emailing the solicitation to key gatekeepers in each community. The gatekeepers were designated to represent various key organizations located within the community, including the 
County Agricultural Extension Service Director, Arts Council Director, Director of Parks and Recreation Department, and the Tourism Office Director. The presence of each of the organizations varied slightly across communities; however, most contained at least three of the four targeted organizations. In addition, the snowball sampling method was applied as these key gatekeepers were asked to engage another gatekeeper from their community to participate, such as the Chamber of Commerce Director or a director of a community development or conservation nonprofit organization. As an incentive for all responding to the survey, each was entered into a drawing for a $\$ 25$ gift certificate to any store in their community.

In keeping with Dillman's suggestions on obtaining adequate response rates with online surveys (2000), an email notification was sent introducing the study and alerting them to the questionnaire that would arrive via email a few days later. Three subsequent emails, sent in three- and four-day intervals, provided a link to the survey, a personal message and photo, and offered the drawing incentive to encourage response.

\section{Results}

Survey efforts resulted in a total of 885 returned and usable surveys from the combined mailing list of 10,000 and the purposive sampling/snowball technique. Of all respondents, $35.7 \%$ were between 51 and 60 years of age, with the majority being over 40 (mean $=46.0$ years). The respondents were predominately female (58\%) and most had obtained at least a four-year degree (68.7\%). Most respondents were long-time residents of their respective communities (mean $=22.9$ years).

Based on the literature, questions representing various components of e-climate were categorized into six groups, or variable categories. Each variable category consisted of 5-10 items (Table 1). These variable categories were defined as: Physical and Business Infrastructure (PBI), Institutional Capacity (IC), Focus of Economic Development (FED), and Training and Assistance (TA) factors (which lie within residents' micro- and mesosystems); Quality of Life ( $Q L)$ and Community Culture (CC) (which lie within residents' exoand macrosystems) (Figure 1).

Analysis was conducted of each group to determine if the individual items, all on the same 5-point Likert-type scale, could be aggregated into a single mean. Interitem correlation and covariance matrices were generated for each aggregation to investigate redundancy within the individual items. Because of low interitem correlations, no items were excluded from any aggregations. Each variable category was tested for internal consistency using Cronbach's coefficient alpha, and all were found to have coefficients of 0.67 or above (Table 1).

Overall, respondents scored e-climate in their respective communities at an above average level, with the means for every component ranging between 3.16 and 3.53 on the 5-point scale. More subtle differences in e-climate components were examined by testing the following eight hypotheses derived from the research questions.

\section{Residential Tenure and Nativity}

The variables residential tenure and nativity were examined to determine if residential tenure, a measure influencing DA, affected the way respondents perceived their community's e-climate. Two hypotheses were tested:

Hypothesis 1a: The longer the resident has lived in the community, the more favorable his/her impression of the community's e-climate.

Hypothesis $1 b$ : The stronger the resident's nativity ties in the community, the more favorable his/her impression of the community's e-climate.

In order to test hypothesis $1 \mathrm{a}$, data for the number of years lived in a community were recoded into five equal distributions (1) 0-5 years, (2) 6-12 years, (3) 13-24 years, (4) 25-39 years, and (5) 40-82 years, and a one-way analysis of variance (ANOVA) was used to test for differences across each e-climate component (Table 2). Results showed significant differences for five of the six components $(p<0.05)$, providing strong support for hypothesis 1a. All four of the e-climate factors within the micro- and mesosystems categories (PBI, IC, FED, and $T A$ ), as well as the $C C$ factor from the exosystem category, were correlated with residential tenure. Interestingly, all post hoc tests showed that people who had lived in a community between 6 and 12 years (category 2) had the least favorable impression of e-climate, while the most favorable perceptions tended to be held by individuals in the year categories 4 and 5 .

Nativity consisted of four categories in order to cover the full range of applicable options. These categories were listed in the questionnaire as (1) native, (2) native family member, (3) both self and family member were natives, and (4) neither. The one-way ANOVA showed there was a statistically significant difference in two components of e-climate across nativity status. Results for the $I C$ factor, $F(3,869)=4.447$, $p=0.004$, were statistically significant. A Tukey's honestly significant difference (HSD) test indicated that the mean score for respondents who considered both themselves and a family member native $(M=3.46, S D=0.748)$ and respondents who considered themselves native $(M=3.36, S D=0.737)$ had a higher opinion of the $I C$ of the county. The results for the $C C$ factor, $F(3,844)=3.513, p=0.015$, were also statistically significant. A Tukey's HSD test indicated that the mean score for respondents who considered both themselves and a family member native $(M=3.27, S D=0.606)$ had a higher opinion of the $C C$ factor than the other three groups. The results provide some support for hypothesis $1 b$, but as nativity did not have a significant relationship with three of the six measures of e-climate, and for the two categories that 
Table I. Reliability Coefficients and Descriptive Statistics for E-climate Components.

Cronbach's Alpha Based on Standardized Items

Physical and Business Infrastructure

Real estate is available and affordable for small businesses to rent or purchase in my county.

Highway access and road maintenance is adequate in my county.

High-speed internet access is available and reliable.

Trusted professional services such as accounting, legal, and tax advice are readily available in or within driving distance of my community.

Good business ideas in my community can attract the necessary financial capital to get them going.

Institutional Capacity

County government is responsive to the needs of those starting a new business.

County government uses outside funding, such as grants, to improve the community as a place to live and work.

County government officials think beyond county borders by collaborating with others in the region.

The nonprofit organizations that serve our county are effective in enhancing economic vitality.

The nonprofit organizations that serve our county are effective in enhancing quality of life.

Focus of Economic Development

The focus of my community's economic development efforts includes ...

new business attraction

supporting existing businesses

working equally with both town and county businesses

considering farms and ranches as part of the business community

considering tourism as part of the business community

helping new businesses get started

Quality of Life

The county has natural resources that make this an enjoyable place to live or visit.

The county has built resources that make this an enjoyable place to live or visit.

The county has cultural resources that make this an enjoyable place to live or visit.

There is lively pedestrian activity during the day in the downtowns of my county.

Community Culture

People in this community support locally owned businesses by choosing to spend money with them whenever possible.

My county recognizes and celebrates people who create and grow local businesses.

Most people in the county support entrepreneurs when they fail and are trying again with a new business.

People in my county understand that small business owners cannot discuss all of the aspects of their business and give that person enough "breathing room" to develop their venture.

The overall pace of change in my county has been quick or intense in the past five years.

My county is getting to be a bedroom community for another county.

New residents to the county can easily integrate into the county's business community if they have good ideas and work ethic.

Ethnic diversity is accepted in this community.

The poorer residents of the county can easily integrate into the county's business community if they have good ideas and work ethic.

Lenders evaluate requests for business loans based on their merit and not on the gender of the person making the loan request.

Training and Assistance

When assistance is needed to make a business decision or help with planning, there is someone to call on for guidance.

Within my county, there are programs to encourage and support entrepreneurs to develop and grow.

Within my county, there is opportunity for business or entrepreneurial training.

Within my county, we have networking and mentoring opportunities for entrepreneurs and local business people.

Youth are provided opportunities to learn about starting a business.

Higher education institutions in the region have programs or personnel committed to supporting business creation and to the needs of small businesses. 
Table 2. E-climate Categories and Key Significant Variables.

\begin{tabular}{|c|c|c|c|c|c|c|}
\hline & PBI & IC & FED & QL & $\mathrm{CC}$ & TA \\
\hline \multicolumn{7}{|c|}{ Residential tenure (years) } \\
\hline $0-5$ & 3.39 & 3.22 & 3.31 & 3.53 & 3.15 & 3.31 \\
\hline $6-12$ & 3.30 & 3.20 & 3.17 & 3.41 & 3.11 & 3.17 \\
\hline $13-24$ & 3.39 & 3.29 & 3.28 & 3.52 & 3.12 & 3.28 \\
\hline $25-39$ & 3.52 & 3.38 & 3.37 & 3.60 & 3.14 & 3.37 \\
\hline $40-82$ & 3.53 & 3.42 & 3.45 & 3.59 & 3.30 & 3.45 \\
\hline$F$ & 3.287 & 3.130 & 3.082 & 1.570 & 3.000 & 3.082 \\
\hline Significance & 0.011 & 0.014 & 0.016 & 0.180 & 0.018 & 0.016 \\
\hline \multicolumn{7}{|c|}{ Volunteer involvement in community } \\
\hline None & 3.31 & 3.10 & 3.12 & 3.23 & 3.12 & 3.06 \\
\hline Low & 3.38 & 3.25 & 3.21 & 3.47 & 3.17 & 3.17 \\
\hline Medium & 3.45 & 3.35 & 3.35 & 3.56 & 3.17 & 3.40 \\
\hline High & 3.54 & 3.40 & 3.53 & 3.71 & 3.23 & 3.69 \\
\hline$F$ & 2.330 & 4.090 & 8.110 & 7.568 & 1.155 & 21.305 \\
\hline Significance & 0.073 & 0.007 & 0.000 & 0.000 & 0.326 & 0.000 \\
\hline \multicolumn{7}{|c|}{ Employment sector } \\
\hline Public & 3.45 & 3.33 & 3.35 & 3.51 & 3.16 & 3.35 \\
\hline Private & 3.44 & 3.17 & 3.21 & 3.53 & 3.12 & 3.25 \\
\hline Nonprofit & 3.40 & 3.45 & 3.40 & 3.66 & 3.26 & 3.54 \\
\hline$F$ & 0.213 & 8.374 & 4.161 & 2.518 & 2.986 & 7.544 \\
\hline Significance & 0.808 & 0.000 & 0.016 & 0.081 & 0.050 & 0.001 \\
\hline
\end{tabular}

Note: $\mathrm{PBI}=$ Physical and Business Infrastructure; IC = Institutional Capacity; FED = Focus of Economic Development; QL = Quality of Life; $\mathrm{CC}=$ Community Culture; TA $=$ Training and Assistance.

did show a significant relationship there was not a wide variance, support for this hypothesis is weak at best. Additionally, because $I C$ and $C C$ are found in different ecological systems, no pattern within the ecological systems framework emerged.

\section{Volunteerism}

The effect of respondents' level of volunteerism (a second measure of DA) on the perception of e-climate was examined through two types of analyses. First, respondents were asked to quantify the number of organizations in which they were currently active from a predetermined list that was developed by the primary researcher based on her longstanding and extensive experience in the field, then further refined through the pretesting process. The results were recoded into four groups based on a standard distribution of data: (1) no involvement (zero organizations, $7.8 \%$ of the sample), (2) low involvement (one to two organizations, $32.4 \%$ of the sample), (3) medium involvement (three to five organizations, 36.8\% of the sample), and (4) high involvement (six or more organizations, $16.9 \%$ of the sample) (Table 2). The effect of amount of involvement was tested using the following hypothesis.

Hypothesis 2a: There is a positive relationship between the number of community organizations in which a resident is involved and perception of community e-climate.
Table 3. E-climate and Community Organizations.

\begin{tabular}{ll}
\hline Organization & Significant E-climate Component \\
\hline Chamber of commerce & $\begin{array}{l}\text { Quality of Life }(p=0.029) \\
\text { Training and Assistance }(p=0.000) \\
\text { Institutional Capacity }(p=0.005) \\
\text { Economic development } \\
\text { Focus of Economic Development } \\
(p=0.000)\end{array}$ \\
& $\begin{array}{l}\text { Training and Assistance }(p=0.000) \\
\text { Local tourism organization }\end{array}$ \\
& $\begin{array}{l}\text { Institutional Capacity }(p=0.049) \\
(p=0.0 \text { I } 8)\end{array}$ \\
& $\begin{array}{l}\text { Quality of Life }(p=0.003) \\
\text { Training and Assistance }(p=0.000)\end{array}$ \\
Community development & Training and Assistance $(p=0.000)$ \\
organization & \\
\hline
\end{tabular}

An ANOVA was used to test for differences according to community organization involvement within each e-climate component. Results showed significant differences for four of the six components $(p<0.05)$, with only the $P B I$ and the $C C$ components showing no differences. All post hoc tests showed that as the level of volunteerism increased, the more favorable the perceptions of e-climate. In addition to the significance between variables, the variance, particularly between those with no involvement and high involvement, begins to reveal more substantive differences, with some exceeding the .6 mark. On the basis of these results, hypothesis 2a was supported. In other words, DA in the form of number of volunteer organizations in which one is involved impacted across all of the EST categories targeted in this study.

The influence of involvement in specific organizations was then examined by focusing on four key organizations related to tourism development within a community: (1) Chambers of Commerce, (2) Economic Development Office, (3) Local Tourism Organization, and (4) Community Development Organization. For the purpose of this study these variables are treated as subcomponents of the same hypothesis.

\section{Hypothesis $2 b$ : There is a positive relationship between involvement in specific community organizations and perception of community e-climate.}

A $t$ test was used to test differences in means between individuals who were involved with each specific organization and individuals who were not. Significant results are displayed in Table 3. Results were an interesting mix of significance. For individuals involved with the Chamber of Commerce, there was a significant relationship with the $Q L$ and $T A$ e-climate categories. For respondents involved with the Economic Development Office, three e-climate categories were significant: $I C, F E D$, and $T A$. For respondents involved with Local Tourism Organizations, both $Q L$ and 
$T A$ were significantly affected e-climate category. For individuals involved with Community Development Organizations, there was a significant relationship with the $T A$ e-climate category (Table 3). On the basis of these results, hypothesis $2 \mathrm{~b}$ received mixed support. While both hypotheses $2 \mathrm{a}$ and $2 \mathrm{~b}$ involved volunteerism, the independent variable within each analysis affected similar e-climate factors. The level of volunteerism as well as volunteering at specific organizations influenced $Q L, T A, I C$, and $F E D$.

\section{Employment Variables}

The influence of employment variables on the perception of e-climate (the third measure of DA) was then examined through five items, including (1) workplace in the community; (2) business ownership; (3) public, private, or nonprofit sector employment; and (4) employment associated with the tourism industry.

Hypothesis 3a: Residents who work within their community will have a more favorable impression of the community's e-climate than residents who work outside of the community.

Hypothesis 3b: Residents who operate their own businesses will have a different impression of the community's e-climate than residents who do not.

Hypothesis 3c: Residents who work in the public and nonprofit sectors will have a more favorable impression of the community's e-climate than residents who do not.

Hypothesis 3d: Residents who work within the tourism industry will have a more favorable impression of the community's e-climate than residents who do not.

For hypothesis $3 \mathrm{a}$, a $t$ test was used to test differences in means between individuals who worked in their community of residency and individuals who did not. Results showed a general lack of support for this hypothesis, with significant differences on only two of the e-climate components: FED and TA $(p<0.05)$. There was a significant difference in the scores for respondents who work in the community regarding the $T A$ factor $(M=3.39, S D=0.766)$ and respondents who did not $(M=3.24, S D=0.722) ; t(872)=2.699, p<0.007$. Results suggest respondents who work in the community have a higher opinion of the $T A$ programs within the county. In both cases, respondents who worked in the community had only a slightly more favorable perception of e-climate as represented on a 5-point Likert-type scale. There were no significant results in the e-climate factors of $P B I, I C, F E D$, $Q L$, and $C C$. On the basis of these results, hypothesis 3a was not supported. This form of DA did not have any impact on perceived e-climate in any of the EST subsystems.

For hypothesis $3 \mathrm{~b}$, a $t$ test was also used to test differences in means between individuals who owned their own business with individuals who did not. Results showed significant differences on only two e-climate components: $I C$ and $F E D$. There was a significant difference in the scores for respondents who owned a business regarding the IC factor $(M=3.20, S D=0.696)$ and respondents who $\operatorname{did} \operatorname{not}(M=$ $3.36, S D=0.7 .34) ; t(872)=3.169, p<0.002$. A significant difference was also recorded for respondents who owned their business regarding the FED factor $(M=3.19, S D=$ $0.716)$ and respondents who did not $(M=3.38, S D=0.785)$; $t(861)=3.562, p<0.000$. Results suggest respondents who do not own a business have a higher opinion of e-climate within the county as it relates to IC and the focus of economic development. So in the case of the two variables reporting significance, they were actually affected in the opposite direction as was hypothesized. There were no significant results in the e-climate factors of $P B I, Q L, C C$, and $T A$ factors. On the basis of these results, hypothesis $3 \mathrm{~b}$ was not supported. As with hypothesis $3 \mathrm{a}$, this form of DA did not have any impact on perceived e-climate in any of the EST subsystems.

A different approach was taken for hypothesis 3c. The sector variable was split into four sectors in order to cover the full range of applicable options. These categories were (1) public sector, (2) private sector, (3) nonprofit sector, and (4) other. Initial analysis was conducted using all four categories, but the number of respondents in the "other" category was so small that these results were excluded from the analysis (Table 2). Results showed significant differences within IC $(p=0.00)$, FED $(p=0.016)$, and TA $(p=0.001)$ components, all found within the micro- and mesosystems of EST. Post hoc tests showed that for all three components, private sector workers had the least favorable impression of e-climate, with the most favorable perceptions reported by public and nonprofit sector workers. For two components, IC and FED, no significant difference was recorded between the public and nonprofit sectors; however, for $T A$ the nonprofit workers were significantly different from the other two components. On the basis of these results, hypothesis $3 \mathrm{c}$ was shown to have mixed support.

For hypothesis $3 \mathrm{~d}$, a $t$ test was used to test differences in means between individuals whose work was associated with the tourism industry and individuals whose work was not. Results showed significant differences on only one e-climate component: There was a significant difference regarding the $T A$ factor in the scores for respondents whose work was associated with tourism $(M=3.45, S D=0.755)$ and respondents whose did not $(M=3.21, S D=0.727) ; t(599)=2.633$, $p<0.009$. Results suggest respondents whose employment is associated with the tourism industry have a higher opinion of the training and assistance programs within the county. Since respondents whose work related to the tourism industry had a significant and favorable perception of only one of the e-climate categories, hypothesis $3 \mathrm{~d}$ was not supported. This hypothesis was also troublesome in that the sample sizes for the two groups were very different in size, with only 
Table 4. Summary of Significant Differences in E-climate Components across Respondent Variables.

\begin{tabular}{|c|c|c|c|c|c|c|c|}
\hline \multirow[b]{2}{*}{ Hypothesis } & \multirow[b]{2}{*}{ Variables } & \multicolumn{4}{|c|}{ Micro and Mesosystems } & \multicolumn{2}{|c|}{ Exosystem } \\
\hline & & $\mathrm{PBI}$ & IC & FED & TA & QL & $\mathrm{CC}$ \\
\hline la & Years lived in county & $x$ & $x$ & $\mathrm{X}$ & & & $\mathrm{X}$ \\
\hline Ib & Nativity & & $\mathrm{x}$ & & & & $x$ \\
\hline $2 \mathrm{a}$ & Level of volunteerism & $x$ & $x$ & $\mathrm{X}$ & $\mathrm{X}$ & $\mathrm{X}$ & \\
\hline $2 b$ & Volunteers in chamber & & & & $\mathrm{x}$ & $x$ & \\
\hline $2 b$ & Volunteers in economic development & & $\mathrm{x}$ & $\mathrm{X}$ & $\mathrm{X}$ & & \\
\hline $2 b$ & Volunteers in tourism office & & $x$ & $x$ & $\mathrm{X}$ & $\mathrm{X}$ & \\
\hline $2 b$ & Volunteers in community development & & & & $\mathrm{X}$ & & \\
\hline $3 a$ & Works in county & & & $\mathrm{X}$ & $\mathrm{x}$ & & \\
\hline $3 b$ & Owns business & & $\mathrm{X}$ & $x$ & & & \\
\hline $3 c$ & Sector & & $x$ & $x$ & $\mathrm{X}$ & & \\
\hline $3 d$ & Works in tourism & & & & $x$ & & \\
\hline 4 & Self-perception as an entrepreneur & & $x$ & & $\mathrm{x}$ & & \\
\hline
\end{tabular}

Note: PBI = Physical and Business Infrastructure; IC = Institutional Capacity; FED = Focus of Economic Development; TA = Training and Assistance; $\mathrm{QL}=$ Quality of Life; CC = Community Culture.

80 respondents having nothing to do with tourism versus 521 who did.

A pattern can be seen among the employment variables in that they most influenced the e-climate factors of $I C, F E D$, and $T A$. These three factors fall within the micro- and mesosystems, the realms of one's community most directly felt. It is not surprising that one's employment, an activity that dictates the extent and type of personal contacts made on a daily basis, would also influence how a resident would see his immediate environment, and namely the institutions and organizations providing assistance to the community.

\section{Entrepreneurial Self-Perception}

One final difference in e-climate perceptions was examined through a self-assessment of entrepreneurial qualities. While not directly related to DA in general, it could be argued that those who perceive themselves as entrepreneurs will be more involved in entrepreneurial activities and programs than those who do not.

\section{Hypothesis 4: Residents who view themselves as entrepreneurial will have a more favorable impres- sion of the community's e-climate than residents who do not.}

Respondents self-reported themselves as entrepreneurial on a 3-point Likert-type scale of (1) absolutely, (2) somewhat, and (3) not really. The one-way ANOVA showed there was a statistically significant difference in two components of e-climate across self-perceptions of entrepreneurialism. Results for the $I C$ factor, $F(2,826)=4.031, p=0.018$, were statistically significant. A Tukey's HSD test indicated that the mean score for respondents who considered themselves "somewhat" entrepreneurial $(M=3.40, S D=0.644)$ had a higher opinion of the $I C$ of the county. The results for the $T A$ factor, $F(2,828)=9.594, p=0.000$, were also statistically significant. A Tukey's HSD test indicated that the mean score for respondents who considered themselves "absolutely" $(M=3.43, S D=0.833)$ and "somewhat" entrepreneurial $(M=3.40, S D=0.711)$ had a significantly higher opinion of the TA programs within the county than those who considered themselves "not really" entrepreneurial $(M=3.17, S D=0.648)$. On the basis of these results, hypothesis 4 was partially supported. Both $I C$ and $T A$ fall within the micro- and mesosystems of EST.

In summary, of the nine hypotheses tested in this study, two showed strong support (hypotheses 1a and 2a), three were not supported (hypotheses 3a, 3b, and 3d), and the remainder showed mixed support (hypotheses $1 \mathrm{~b}, 2 \mathrm{~b}, 3 \mathrm{c}$, and 4) (Table 4). Specifically, within the first category of hypotheses (and DA), length of residential tenure was found to be a strong predictor of variation in a community's perceptions of e-climate, but nativity was only weakly supported. Volunteerism, as the second category of hypotheses (and DA), was shown to have a mixed effect on perceptions of e-climate. An increase in the overall amount of volunteerism was shown to have a positive effect on perceptions of e-climate across all factors and across all systems of EST. However, specific types of volunteerism did not demonstrate the same influence. In the third category of DA, employment, three of the four employment variables used did not appear to strongly influence the respondents' perceptions of e-climate, with no single factor being consistently significantly different across all variables or all EST subsystems. Where differences did occur, public and nonprofit employment sectors generally had more favorable impressions than their private sector counterparts. Finally, perceptions of 
personal entrepreneurial spirit had limited affect on how respondents perceived e-climate, with significant differences seen only with the $I C$ and the $T A$ factors, both located within the micro- and mesosystems of EST.

\section{Discussion and Conclusions}

In this article, the authors have sought to examine residents' perceptions of e-climate in rural North Carolina, and whether those perceptions were influenced by residential tenure and nativity, level of community involvement through volunteerism, type of employment, and entrepreneurial selfperception. Each of these variables, with the exception of entrepreneurial self-perception, are factors that would potentially influence an individual's DA within his or her community. Understanding e-climate in rural communities is vital, given the close relationship between entrepreneurship and tourism. The unique contribution of this article to the overall tourism literature has been to utilize DA (a measure of depth), and EST (a framework of breadth), together to explore the concept of entrepreneurial climate. While the region being studied and the sample population is by no means representative of rural tourism overall, the study has revealed some interesting relationships and results.

For the first category of hypotheses that examined the relationship between perceived e-climate as a component of EST and the DA category of residential tenure and nativity, the literature targeting residents' tenure was further supported (Florin and Wandersman 1990; Jurowski and Brown 2001; Um and Crompton 1987). Overall, residential tenure played a greater role than nativity in influencing perceived e-climate, which, interestingly, is similar to findings related to resident support of tourism (Andereck et al. 2005; McGehee and Andereck 2004; Jurowski and Brown 2001; Sirakaya, Teye, and Sonmez 2002). Another possible explanation for this result may lie in the unique nature of rural North Carolina. Unlike many rural areas in the United States, rural North Carolina has seen a sharp increase in population size and sociodemographic diversity from outside the state over the past 20 years. While there are still many rural communities across the United States where a few matriarchal or patriarchal families exert a great deal of political and social power, the more transient nature of rural North Carolina has perhaps weakened those families. This is in keeping with Beugelsdijk and Noorderhaven's (2002) notion of regional differences and the need for individualized research. Although there may be a theoretical explanation for this, a methodological explanation may be that a categorical scale was used for nativity in this study (as opposed to a yes/no dummy variable). This more complex approach revealed a weaker relationship. Regardless, support for residential tenure as influential does reinforce the DA literature (Huang and Tsai 2010; Fadahunsi, Smallbone, and Supri 2000; Perry 1999).

An interesting pattern that occurred across the three time periods ( $0-5$ years, $6-12$ years, +12 years) that has not been found in previous research. Both the categories 0-5 and +12 years exhibited a stronger influence on e-climate than the middle time period of 6-12 years. While there does not appear to be any previous literature to support this idea, one could hypothesize that those who have been residents for less than 5 years are still in a new honeymoon period with the community. Those who have lived in the community for more than 12 years may be invested in and content with their lifestyle and their surroundings. This is only speculation on the part of the authors, but it would be interesting to further test this idea.

Community involvement in the form of volunteerism, as the second category of hypotheses, was shown to have a mixed effect on perceptions of e-climate as well as mixed support the EST framework. The number of organizations in which respondents were involved in volunteerism did have a relationship with e-climate perceptions (hypothesis $2 \mathrm{a}$ ). This finding supports previous research (van Laere and Heene 2003), as well as the more specific assertion that DA does affect perceived e-climate. The more involved respondents were in a variety of organizations, the greater their perception of entrepreneurial opportunities and entrepreneurship support within the community.

Volunteerism involvement in the specific organizations isolated by the authors (Chambers of Commerce, Economic Development Office, Local Tourism Organization, and Community Development Organization) did not exhibit a consistent relationship with perceived e-climate overall (hypothesis 2b), but there was a consistent relationship between involvement in any of these organizations and the e-climate variable Training and Assistance (TA). This is in keeping with the work of Lerner and Haber (2000), who found that institutional support through training events and activities was vital to a positive e-climate. Interestingly, it also coincides with the research on the role of training in tourism (Echtner 1995; Haber and Reichel 2007; Peters 2005; Victurine 2000). Apparently, these organizations must act as important channels of information and/or sources of entrepreneurial TA, so by their involvement people were aware of training opportunities that perhaps others were not. If this is the case, these organizations perform as gatekeeper organizations, holding the keys to knowledge about available training opportunities. Interestingly, the single most influential type of organization was the Economic Development Office (EDO). This is not terribly surprising, as the role of an EDO is to support business expansion within the community. Respondents associated with this organization most likely had the greatest access to e-climate related programs. It is important to note that the relationship was not a strong and consistent one.

In the third category of hypotheses, employment, three of the four variables did not appear to strongly influence the respondents' perceptions of e-climate, as no single factor was consistently significantly different across all variables, nor across all subsystems of EST. Results suggest respondents 
who work in the community (hypothesis 3a) have a higher opinion of the Training and Assistance programs within the county. Those who are self-employed have a lower opinion of e-climate within the county as it relates to $I C$ and the $F E D$. In the case of the two variables reporting significance, hypothesis $3 \mathrm{~b}$ was supported. The authors theorize that a business owner, who deals daily with management issues, would have more interaction with and knowledge of the e-climate elements that potentially support or thwart entrepreneurial activity. When evaluating employment by sector (private, public, and nonprofit), where significant differences did occur (Institutional Capacity, Focus on Economic Development, and Training and Assistance), public and nonprofit employment sectors generally had more favorable impressions than their private sector counterparts (hypothesis $3 c$ ). An explanation for this finding could be that public/ nonprofit sector organizations are often the institutions that shape the e-climate through their programs and policies.

The last employment-related hypothesis examined the relationship between participation in the tourism industry and perceived e-climate. Results suggest respondents whose employment was associated with the tourism industry had a higher opinion of the Training and Assistance programs within the county than those who did not. This indicates the close connection between entrepreneurship and the tourism industry as argued by Koh (2002). For the final hypothesis involving entrepreneurial self-perception, only two elements of e-climate were significantly affected: Institutional Capacity and Training and Assistance, both of which lie within a person's EST micro- and mesosystems. For those who perceived themselves as either somewhat or highly entrepreneurial, these two components of e-climate were viewed favorably.

In addition to an examination of support for the hypotheses delineated for this study, it is also valuable to analyze the individual e-climate categories for patterns and consistencies, especially as they relate to the various systems within EST as outlined in the final research question of this study: Are there patterns in the way the elements of e-climate are viewed according to the structure of Ecological Systems Theory?

Overall, the e-climate categories found to be influenced by the four DA factors were Training and Assistance, Institutional Capacity, and Focus of Economic Development. While the literature is not consistent (Lerner and Haber 2000), it could be explained that these e-climate categories require a commitment to a certain level of involvement. The authors theorize that the elements encompassed in these e-climate categories are common in that they are reflective of particular community service institutions. Namely, local government agencies, nonprofit organizations, and educational institutions have a mission to serve the community in a number of ways. Their programs and outcomes are more visible and susceptible to critique. Additionally, these e-climate factors are within residents' microsystem and mesosystem of
EST, the ecological realm most directly felt by an individual. A resident's networks are located within her or his microand mesosystems, which supports the notion that the density of networks influences her or his perception of the environment.

Two of the three e-climate categories that were regarded similarly by respondents, Quality of Life and Community Culture, are conceptual in nature, albeit influential for entrepreneurial activity (Bolton and Thompson 2004; Chatman, Atlman, and Johnson 2008; Markley, Macke, and Luther 2005). Both of these factors are part of a resident's exosystem; therefore, it may be plausible that residents perceive these elements of a community bilaterally because they are "assumed" and so inherent in community's daily transactions that their influence is not directly perceived.

This study was not without its limitations. The sample for the study is not representative, and therefore not generalizable. In particular, the sample overrepresents those who are involved in the tourism industry. In one sense, this is quite advantageous for those of us interested in tourism-related e-climate, but it is also limiting in terms of our ability to make comparisons between tourism and nontourism-related businesses. The skewed sample may be indicative of the sampling method, in that the gatekeepers who were originally solicited to distribute the survey instrument were involved in tourism development. Additionally, the sample represents one snapshot in time, and a more longitudinal approach to measuring resident attitudes, such as the approach used in Huh and Vogt (2008), would yield more insight into community perception of e-climate through changes in the various micro-, meso-, exo-, and macrosystems.

This study has inspired a number of ideas for future research in community-based tourism. This study analyzed 36 e-climate elements that were grouped into six factors. Future studies may refine these elements. Additionally, instead of matching e-climate factors with the systems within EST, future models may explore the association of individual elements within EST. There is room for a more exploration of the theoretical concept of DA and how it interconnects with and informs EST. Methodological triangulation of perceived e-climate with analysis of the actual policies and programs that are in place might provide additional information that would delineate the real from the perceived. In particular, the inclusion of qualitative research involving interviews of entrepreneurs might reveal greater depth and detail in this area. While the instrument was adapted from established measures of e-climate, as well as elements of both DA and EST, measurement of this complex web of tangible and intangible elements can surely be refined and tested. Updated elements from the EST and DA literature might be merged with the existing e-climate variables to continue to blend these conceptual frameworks. There is also room for additional theoretical perspectives to be included in the study of tourism and e-climate. For example, social capital theory has 
potential, particularly in the area of bridging and bonding social capital (McGehee et al. 2009).

Further research on e-climate is warranted because it so profoundly affects an entrepreneur's activities. E-climate elements could be explored via regression modeling and structural equation modeling (SEM) to discover which elements most influence rural tourism development. Future research might also explore whether e-climate affects social and private sector entrepreneurs differently. From an applied standpoint, if a community were to use e-climate assessments to gauge the status of their community, it might subsequently evaluate at regular intervals to see if strategies to empower locally grown enterprises are working. Finally, Beugelsdijk and Noorderhaven's (2002) notion of regional differences could be tested to determine if regions with certain entrepreneurial climate elements are linked more closely with economic growth than those that are not.

\section{Declaration of Conflicting Interests}

The author(s) declared no potential conflicts of interest with respect to the research, authorship, and/or publication of this article.

\section{Funding}

The author(s) received no financial support for the research, authorship, and/or publication of this article.

\section{References}

Andereck, K. L., K. M. Valentine, R. C. Knopf, and C. A. Vogt. (2005). "Residents' Perceptions of Community Tourism Impacts." Annals of Tourism Research, 32 (4): 1056-76.

Barr, T. (1990). "From Quirky Islanders to Entrepreneurial Magnates: The Transition of the Whitsundays." Journal of Tourism Studies, 1 (2): 26-32.

Bauer, J. W., and E. M. Dolan. (2011). "Theories for Studying Rural Families and Work." In Rural Families and Work, edited by J. W. Bauer and E. M. Dolan. New York: Springer, pp. 17-35.

Berk, L. E. (2000). Child Development. 5th edition. Boston, MA: Allyn and Bacon.

Beugelsdijk, S., and N. Noorderhaven. (2002). "Entrepreneurial Attitude and Economic Growth: A Cross-section of 54 Regions." Paper presented at the 2002 Conference of the European Regional Science Association in Dortmund Germany.

Bolton, B., and J. Thompson. (2004). Entrepreneurs-Talent, Temperament, Technique. 2nd edition. Oxford: Elsevier Butterworth Heinemann.

Braun, P., and M. Hollick. (2006). "Tourism Skills Delivery: Sharing Tourism Knowledge Online.” Education and Training, 48 (8/9): 693-703.

Bronfenbrenner, U. (1979). Ecology of Human Development: Experiments by Nature and Design. Boston, MA: Harvard University Press.

Chatman, D., I. Atlman, and T. Johnson. (2008). "Community Entrepreneurial Climate: An Analysis of Small Business Owners' Perspectives in 12 Small Towns in Missouri, USA." Journal of Rural and Community Development, 3: 60-77.
Crane, F., and M. Meyer. (2006). "The Entrepreneurial Climate in Canada: The Entrepreneur's Viewpoint." Journal of Small Business and Entrepreneurship, 19 (3): 223-32.

Deller, S. C., and J. McConnon, Jr. (2009). "Microenterprises and Economic Growth: A Panel Study of the US States 1977 to 1997." Applied Economics Letters, 16: 1307-12.

Dillman, D. (2000). Mail and Internet Surveys: The Tailored Design Method. New York: John Wiley.

Echtner, C. M. (1995). "Entrepreneurial Training in Developing Countries." Annals of Tourism Research, 22 (1): 119-34.

Elder, G. H. (1974). Children of the Great Depression: Social Change in the Life Experience. Chicago: University of Chicago Press.

Erickson, B. (2003). "Social Networks: The Value of Variety." Contexts, 2 (1): 25-31.

Fadahunsi, A., D. Smallbone, and S. Supri. (2000). "Networking and Ethnic Minority Enterprise Development: Insight from a North London Study." Journal of Small Enterprise Development, 7 (3): 228-40.

Farrell, B. H., and L. Twining-Ward. (2004). "Reconceptualizing Tourism." Annals of Tourism Research, 31 (2): 274-95.

Fennell, D. A., (2002). “Ecotourism: Where We've Been; Where We're Going." Journal of Ecotourism, 1 (1): 1-6.

Fennell, D. A., and R. W. Butler. (2003). "A Human Ecological Approach to Tourism Interactions." International Journal of Tourism Research, 5 (3): 197-210.

Ferrari, G., J. Mondéjar-Jiménez, and M. Vargas-Vargas. (2010). "Environmental Sustainable Management of Small Rural Tourist Enterprises." International Journal of Environmental Research, 4 (3): 407-14.

Flora, C. B., and J. L. Flora. (1993). "Entrepreneurial Social Infrastructure: A Necessary Ingredient.” Annals of Tourism Research, 529: 48-58.

Florin, P., and A. Wandersman, eds. (1990). "Citizen Participation, Voluntary Organizations, and Community Development: Insights for Empowerment through Research." American Journal of Community Psychology, 18: 41-177.

Freudenburg, W. (1986). "The Density of Acquaintanceship: An Overlooked Variable in Community Research?" American Journal of Sociology, 92 (1): 27-63.

Goetz, S. J., M. D. Partridge, S. Deller, and D. Fleming. (2010). "Evaluating Rural Entrepreneurship Policy." Journal of Regional Analysis and Policy, 40: 20-33.

Haber, S., and A. Reichel. (2007). "The Cumulative Nature of the Entrepreneurial Process: The Contribution of Human Capital, Planning and Environment Resources to Small Venture Performance." Journal of Business Venturing, 22 (1): 119-45.

Hao, H., P. Long, and J. Kleckley. (2011). "Factors Predicting Homeowners' Attitudes toward Tourism: A Case of a Coastal Resort Community." Journal of Travel Research, 50 (6): 627-40.

Henderson, D. E. (2009). "Building Community: Partnering with Businesses Both Big and Small." NACCHO Exchange, 8 (1): $10-11$.

Hillery, G. (1955). "Definition of Community: Areas of Agreement." Rural Sociology, 20: 111-23. 
Hitchcock, M. (2000). "Ethnicity and Tourism Entrepreneurship in Java and Bali." Current Issues in Tourism, 3 (3): 204-25.

Huang, C. Y., and Y. S. Tsai. (2010). "Effects of Friend-Making Resources/Costs and Remembering on Acquaintance Networks." Physica A: Statistical Mechanics and Its Applications, 389 (3): 604-22.

Huh, C., and C. Vogt. (2008). "Changes in Residents' Attitudes toward Tourism over Time: A Cohort Analytical Approach." Journal of Travel Research, 46: 446-55.

Hung, K., E. Sirakaya-Turk, and L. J. Ingram. (2011). "Testing the Efficacy of an Integrative Model for Community Participation." Journal of Travel Research, 50 (3): 276-88.

Hwang, D., W. P. Stewart, and D. Ko. (2012). "Community Behavior and Sustainable Rural Tourism Development." Journal of Travel Research, 51: 328-41.

Jurowski, C. (1998). "A Study of Community Sentiments in Relation to Attitudes toward Tourism Development." Tourism Analysis, 3 (1): 17-24.

Jurowski, C., and D. O. Brown. (2001). "A Comparison of the Views of Involved versus Noninvolved Citizens on Quality of Life and Tourism Development Issues." Journal of Hospitality and Tourism Research, 25 (4): 335-70.

Kirsten, M., and C. M. Rogerson. (2002). "Tourism, Business Linkages and Small Enterprise Development in South Africa." Development Southern Africa, 19 (1): 29-59.

Kline, C. (2006). "Tourism Extension Internal Needs Assessment" [technical report]. North Carolina State University Department of Parks, Recreation and Tourism Management.

Koh, K., and T. Hatten. (2002). "The Tourism Entrepreneur: An Overlooked Player in Tourism Development Studies." International Journal of Hospitality and Tourism Administration, 3 (1): 21-48.

Koh, K. (2002). "Explaining a Community Touristscape: An Entrepreneurism Model." International Journal of Hospitality and Tourism Administration, 3 (2): 21-48.

Lacitignola, D., I. Petrosillo, M. Cataldi, and G. Zurlini. (2007). "Modelling Socio-ecological Tourism-Based Systems for Sustainability." Ecological Modelling, 206 (1-2): 191-204.

Larsen, R., E. Calgaro, and F. Thomalla. (2011). "Governing Resilience Building in Thailand's Tourism-Dependent Coastal Communities: Conceptualising Stakeholder Agency in Socialecological Systems." Global Environmental Change, Part A: Human and Policy Dimensions, 21 (2): 481-91.

Lerner, M., and S. Haber. (2000). "Performance Factors of Small Tourism Ventures: The Interface of Tourism, Entrepreneurship, and the Environment." Journal of Business Venturing, 16: 77-100.

Litchenstein, G. A., T. S. Lyons, and N. Kutzhavnova. (2004). "Building Entrepreneurial Communities: The Appropriate Role of Enterprise Development Activities." Journal of Community Development Society, 35 (1): 5-24.

Lordkipanidze, M. (2002). "Enhancing Entrepreneurship in Rural Tourism for Sustainable Regional Development: The Case of Söderslätt Region, Sweden." Master's thesis, The International Institute for Industrial Environmental Economics Reports, 10. Lund University, Lund, Sweden.
Loveridge, S., and D. Nizalov. (2007). "Operationalizing the Entrepreneurial Pipeline Theory: An Empirical Assessment of the Optimal Size Distribution of Local Firms." Economic Development Quarterly, 24: 244-62.

Low, S. (2004). "Regional Assets Indicators: Entrepreneurship Breadth and Depth Indicators." Center for the Study of Rural America, Federal Reserve of Kansas City. http:/www.kansascityfed.org/ publications/research/mse/regional-asset-indicators.cfm.

Macbeth, J., D. Carson, and J. Northcote. (2004). "Social Capital, Tourism, and Regional Development: SPCC as a Basis for Innovation and Sustainability." Current Issues in Tourism, 7 (6): 502-22.

Macke, D. (2007). "Energizing Entrepreneurs: Lessons from the Field." In Entrepreneurship and Local Economic Development, edited by N. Walzer. Plymouth, UK: Lexington Books, pp. 211-31.

Markley, D., D. Macke, and V. Luther. (2005). Energizing Entrepreneurs: Charting a Course for Rural Communities. Lincoln, NE: Heartland Center for Leadership Development.

Matthews, R., R. Pendakur, and N. Young. (2009). "Social Capital, Labour Markets, and Job-Finding in Urban and Rural Regions: Comparing Paths to Employment in Prosperous Cities and Stressed Rural Communities in Canada." Sociological Review, 57 (2): 306-30.

McGehee, N. G., and K. L. Andereck. (2004). "Factors Predicting Rural Residents' Support of Tourism." Journal of Travel Research, 43 (2): 131-40.

McGehee, N. G., and C. S. Kline. (2008). "Entrepreneurship and the Rural Tourism Industry: A Primer.” In Building Community Capacity for Tourism Development, edited by G. Moscardo. Oxfordshire, UK: CABI.

McGehee, N. G., S. Lee, T. L. O’Bannon, and R. R. Perdue. (2009). "Tourism-related Social Capital and Its Relationship with Other Forms of Capital: An Exploratory Study." Journal of Travel Research, 49 (4): 486-500.

McKercher, B. (1999). "A Chaos Approach to Tourism.” Tourism Management, 20: 425-34.

North Carolina Department of Commerce. (2011). 2011 North Carolina Fast Facts: 2011 Impact of Visitor Spending. http://www. nccommerce.com/tourism/research/nc-fast-facts.

Obst, P., S. G. Smith, and L. Zinkiewicz. (2002). “An Exploration of Sense of Community, Part 3: Dimensions and Predictors of Psychological Sense of Community in Geographical Communities.” Journal of Community Psychology, 30 (1): 119-33.

Padilla, M. B., V. Guilamo-Ramos, A. Bouris, and A. Reyes. (2010). "HIV/AIDS and Tourism in the Caribbean: An Ecological Systems Perspective." American Journal of Public Health, 100 (1): 70-77.

Pages, E., and D. Markley. (2004). "Understanding the Environment for Entrepreneurship in Rural North Carolina." A Report to NC Rural Economic Development Center. http://www.ncruralcenter .org/index.php?option=com_content $\&$ view=article \&id=174\&I temid=168 (accessed October 27, 2012).

Panel Study of Entrepreneurial Dynamics: Study Design. (n.d.). Clemson University Website. http://psed.info/. 
Perkins, D. D. (1995). "Speaking Truth to Power: Empowerment Ideology as Social Intervention and Policy." American Journal of Community Psychology, 23: 765-94.

Perkins, D. D., P. Florin, R. C. Rich, A. Wandersman, and D. M. Chavis. (1990). "Participation and the Social and Physical Environment of Residential Blocks: Crime and Community Context." American Journal of Community Psychology, 17: 83-115.

Perry, M. (1999). Small Firm and Network Economies. London: Routledge.

Peters, M. (2005). "Entrepreneurial Skills in Leadership and Human Resource Management Evaluated by Apprentices in Small Tourism Businesses." Education and Training, 47 (8/9): 575-91.

Rightmyre, V. M., T. G. Johnson, and D. Chatman. (2004). "Growing Entrepreneurship from the Ground Up: A CommunityBased Approach to Growing Your Own Business." http://www. cpac.missouri.edu/topics/rural_entrepreneurship/.

Roosa, M. W., R. White, K. H. Zeiders, and J. Tein. (2009). “An Examination of the Role of Perceptions in Neighborhood Research.” Journal of Community Psychology, 37 (3): 327-41.

Russell, R., and B. Faulkner. (1999). "Movers and Shakers: Chaos Makers in Tourism Development." Tourism Management, 20: 411-23.

Russell, R., and B. Faulkner. (2004). "Entrepreneurship, Chaos and the Tourism Area Life Cycle." Annals of Tourism Research, 31 (3): 556-79.

Sirakaya, E., V. Teye, and S. Sonmez. (2002). "Understanding Residents' Support for Tourism Development in the Central Region of Ghana." Journal of Travel Research, 41 (1): 57-67.

Stevens, H. M., and M. D. Partridge. (2011). "Do Entrepreneurs Enhance Economic Growth in Lagging Regions?" Growth and Change, 42 (4): 431-65.

Um, S., and J. L. Crompton. (1987). "Measuring Resident's Attachment Levels in a Host Community." Journal of Travel Research, 26: 27-29.

Van Laere, K., and A. Heene. (2003). "Social Networks as a Source of Competitive Advantage for the Firm." Journal of Workplace Learning, 15 (6): 248-58.

Victurine, R. (2000). "Building Tourism Excellence at the Community Level." Journal of Travel Research, 38: 221-29.

Volker, S., and J. Sorée. (2003). "Fighting over Tourists: A Case Study of Competing Entrepreneurs in a Small Town in Belize." In Tourism Development and Local Participation in Latin
America, edited by H. Dahles and L. Keune. New York: Cognizant Communications Group, pp. 101-14.

Wilson, S., D. Fesenmaier, J. Fesenmaier, and J. C. Van Es. (2001). "Factors for Success in Rural Tourism Development." Journal of Travel Research, 40 (2): 132-38.

Woodside, A. G., M. Caldwell, and R. Spurr. (2006). “Advancing Ecological Systems Theory in Lifestyle, Leisure, and Travel Research.” Journal of Travel Research, 44 (3): 259-72.

Woodside, A. G., and D. Martin. (2008). “Applying Ecological Systems and Micro-tipping Point Theory for Understanding Tourists' Leisure Destination Behavior." Journal of Travel Research, 47 (1): 14-24.

Zach, F. (2012). "Partners and Innovation in American Destination Marketing Organizations." Journal of Travel Research, 51 (4): 412-25.

Zimmerman, M. A. (1990). "Taking Aim on Empowerment Research: On the Distinction between Psychological and Individual Conceptions." American Journal of Community Psychology, 18 (1): 169-77.

\section{Author Biographies}

Carol Kline is an assistant professor at the Center for Sustainable Tourism/Recreation and Leisure Studies at East Carolina University and has worked in the area of rural tourism planning for nearly twenty years. Her work focuses on the interplay between tourism entrepreneurs and their community climate, as well as sustainable farm and food tourism, and niche forms of tourism in burgeoning destinations, such as the scientific tourism market.

Nancy Gard McGehee is a sociologist with field experience in rural tourism development. She is currently an Associate Professor and J. Willard and Alice S. Marriott Junior Faculty Fellow of Hospitality Management in the Hospitality and Tourism Management Department at Virginia Tech.

Shona Paterson is a $\mathrm{PhD}$ candidate in the Coastal Resources Management Program at East Carolina University and holds a Master's in Tropical Coastal Management from the University of Newcastle-upon-Tyne. Her research interests include coastal resilience, community governance, and collective action.

Jerry Tsao graduated from East Carolina University with an MA in International Studies His research focuses on social networks and entrepreneurial factors that promote sustainable tourism destinations, with a concentration on social and economic development. 